\title{
The Molecular Conformations and Intermolecular Correlations in Positional Isomers 1- and 2- Propanols in Liquid State Through Neutron Diffraction
}

\author{
R.N. Joarder \\ Jadavpur University \\ India
}

\section{Introduction}

In the case of molecular liquids meaning of structure is two-fold-first is molecular units, their structure or conformation and second is average spatial arrangement of molecules or liquid structure. A liquid can not have structure in the same sense as a crystallographic solid has since the positions of the molecules continuously change and any local configuration will change over a short interval of time. In spite of that there is a possibility that, on average, a particular configuration dominates over the others, especially in H-bonded liquids. Alcohols are good examples where small labile clusters continually break and reform at a mean time interval. During the last few decades, the structural correlations in associative liquids, particularly, those involving H-bonding have been extensively studied, thanks to the successful application of statistical mechanical methods together with improved methods of experimental techniques (Diffraction, Raman, NMR) and Computer simulations. In spite of extensive developments some areas remain unclear even today. For example, the structure and structure related properties of liquid alcohols with large sized molecular species sill remain somewhat controversial. Alcohols are important group of compounds widely used as solvents and many of their properties are due to the existence of intermolecular hydrogen bonds. Though alcohols have amphiphilic molecular structures, the presence of hydrophobic groups do not allow them to form tetrahedral structure like that in water, rather they form H-bonded chains. The diffraction techniques, both $\mathrm{x}$-ray and neutron have yielded useful direct information about the microscopic average structure and near neighbor correlations. The computer simulations, NMR also provide very useful information about their microscopic structure and dynamics. Although all the techniques yield general nature of the liquid structure as chains there is lot of disagreement in the detailed nature of the chain or cluster formed due to H-bonding. In solid and gaseous phases, alcohol structures are now well established. In liquid state however, the situation is still open in view of differences in the results of diffraction and other techniques (Svishchev \& Kusalik, 1993; Jorgensen, 1986; Magini et al, 1982; Sarkar \& Joarder, 1993, 1994; Benson, 1996).

In the mono-alcohol series two lowest members, methanol and ethanol in liquid phase have been studied quite extensively. The third member of the family, propanol $\left(\mathrm{C}_{3} \mathrm{H}_{7} \mathrm{OH}\right)$ exists 
in two stereo-isomeric forms n-propanol (1-propanol or 1P) and isopropanol (2-propanol or $2 \mathrm{P})$ and are relatively less studied even today. The investigation of their molecular conformation and intermolecular correlations, in liquid state is all the more interesting because they have significant differences in thermodynamic and other properties. The significant property differences could be attributed to differences in structures, conformational as well as associational. Therefore, a careful and detailed investigation of these two isomeric liquids is very important. Now, even today, most detailed information about molecular structure and average liquid structure is by diffraction techniques, $x$-ray or neutron. The neutron diffraction is especially useful because it can yield molecular conformation with correct hydrogen positions and intermolecular correlations. Though $\mathrm{x}-$ rays can not see hydrogen positions accurately, the skeleton of the intermolecular structure is however more prominently visible (Sarkar \& Joarder, 1993, 1994; Narten \& Habenchuss, 1984). So a combination of two techniques is very useful in these studies.

In this short resume we discuss the use of neutron diffraction data sublimented by recent $x-$ ray diffraction data in the detailed investigation of molecular conformation and molecular association of two propanols in liquid state at room temperature (RT). The Monte-Carlo (MC) simulations based on optimized intermolecular potential functions for liquid alcohols including 1- and 2-propanols were carried out long time back (Jorgensen, 1986) and this showed more or less similar chain molecular association for all the members. The molecular dynamics (MD) simulation of 1-propanol in liquid state has also been reported (Akiyama et al, 2004) and the results are comparable with diffraction results. The ab initio calculations of connectivity effects on the clusters of 1-propanol and other alkanol compounds are also available (Sum \& Sandler, 2000).

\section{1- and 2-propanols: Thermodynamic and structural differences}

In crystalline phase at low temperatures, and also in glassy state, a number of investigations (Talon et al, 2001; Ramos et al, 2003; Talon et al, 2002; Cuello et al, 2002) on the structural differences between the two isomers of propanol and their possible influence on the thermodynamic properties are now available. It is noteworthy that 2-propanol possesses a much larger specific heat than 1-propanol, main reason being the significant larger Debye contribution in 2-propanol.The x-ray and neutron scattering experiments (Talon et al, 2001; Talon et al, 2002; Cuello et al, 2002) have been reported on samples of the glassy and crystalline states. The structural analysis of crystalline state assign a triclinic structure for 1propanol and a monoclinic structure for 2-propanol. It is possible that the property differences in two propanols in glassy and crystalline states may be attributed to the influence of the position of the hydroxyl $\left(\mathrm{OH}^{-}\right)$group on the elastic constants of the $\mathrm{H}$ bonded network, constituent with the atomic structures of 1- propanol and 2-propanol.

In liquid state too, differences in thermodynamic and other properties are clearly visible (Sahoo, 2011, vide Table-1). Both molecular units however show close values for relevant molecular properties such as van der Waals volumes ( $124.8 \AA^{3}$ for 1-propanol and $127.7 \AA^{3}$ for 2-propanol) and molecular electric dipole moments $\left(\sim 1.66 \times 10^{-30}\right.$ esu-cm), the overall molecular 'shape 'being the property most affected by such chemical changes. The molecular structural or conformational differences are likely to result in significant differences in basic thermodynamic and other properties. It is therefore indeed interesting to see how the change in the position of a chemical functional group $(\mathrm{OH})$ from one atom to 
another within the same structural unit changes significantly the thermodynamic and other properties of the liquid. It is true that such comparative studies on the structural correlations of 1- and 2-propanol in liquid state are still rare.

\begin{tabular}{|l|c|c|}
\hline Properties & 1-propanol & 2-propanol \\
\hline Density $(\rho)$ in $g m / c . c$ & 0.803 & 0.785 \\
Melting point $\left(\mathrm{T}_{\mathrm{m}}{ }^{\circ} \mathrm{C}\right)$ & -125 & -88 \\
Flash point $\left(\mathrm{F} . \mathrm{P}^{\circ} \mathrm{C}\right)$ & 15 & 11.7 \\
Boiling Point $\left(\mathrm{T}_{\mathrm{b}}{ }^{\circ} \mathrm{C}\right)$ & 97 & 82 \\
Glass transitiontemperature $\left(\mathrm{T}_{\mathrm{G}}{ }^{\circ} \mathrm{C}\right)$ & -175 & -158 \\
Isothermal Compressibility $\left(\chi_{\mathrm{T}} \times 10^{-5}\right) /$ atmos at $25^{\circ} \mathrm{C}$ & 121 & 112 \\
Heat capacity $\left(\mathrm{C}_{\mathrm{p}}\right)$ in cal $/ \mathrm{mol} . \mathrm{deg}$ & 33.70 & 36.06 \\
Viscosity $(\eta)$ in $\mathrm{mPa}$ at2 $20^{\circ} \mathrm{C}$ & 1.94 & 2.37 \\
Entropy of vaporisation at $\mathrm{T}_{\mathrm{b}}\left(\Delta \mathrm{S}_{\mathrm{v}}\right)$ in cal $/ \mathrm{mol}$ & 28.43 & 31.35 \\
Dielectric constant $(\varepsilon)$ & $20.1\left(25^{\circ} \mathrm{C}\right)$ & $20.18\left(20^{\circ} \mathrm{C}\right)$ \\
\hline
\end{tabular}

Table 1. Properties of liquid 1- and 2-propanols

\section{Molecular conformational studies}

The propanol is the smallest monoalcohol showing two stereoisomers in crystalline and glassy phases and also likely in liquid phase and so allow us to make comparative study on the effect of rearrangement of the H-bonded structures using diffraction data (both x-ray and neutron). The molecules are however quite large in size and H-bonding being intermolecular, there is considerable amount of overlapping between some intra and intermolecular contributions. The separation of these terms are obviously tricky. Only a few diffraction experiments are so far done on them in liquid state and successfully analyzed. The structures in gaseous phases were obtained by electron diffraction as early as in sixties (Abdel Aziz \& Rogowski, 1964).The results showed molecular structures significantly different in two propanols (ccco-chain in trans-configuration for 1-propanol and tetrahedraangled to middle c-atom in 2-propanol). The first x-ray diffraction on liquid 1-propanol was reported in 1977 (Mikusinska-Planner, 1977) and molecular conformation was shown to be somewhat spherical in shape. The neutron diffraction works on liquid 2-propanol at low temperatures (190K-275K) were done by Howells et al (Zetterström et al, 1991, 1994) with TOF (time of flight) neutron data. The high-q data were directly used to fit the molecular structure of liquid 2-propanol. The molecular parameters like $\mathrm{r}_{\mathrm{C}_{2} \mathrm{O}}, \mathrm{r}_{\mathrm{OD}}$ and $\mathrm{C}_{2} \mathrm{OD}$ were quite smaller compared to those for gaseous phase (Abdel Aziz \& Rogowski, 1964) and also for other alcohols in liquid phase (Sarkar \& Joarder, 1993, 1994; Adya et al, 2000). Further the parameters varied considerably over the temperature range though such parameters are expected to be only weakly temperature dependent (Montague \& Dore, 1986; Sahoo et al, 2010). In liquid state small variation due to thermal stretching for $r_{O D}$ is not unlikely. The $x-$ ray diffraction works on liquid 1-and 2- propanols (in pure and aqueous solution) were carried out in the recent past (Takamuku et al, 2002, 2004). The molecular parameters were consistent in the two cases though accurate locations of $\mathrm{H}$ - positions could not be ascertained. For 1-propanol molecule, the authors considered cis, trans and gauche 
conformations and gauche conformation was shown to be more favorable though some small population of trans was not ruled out. In the analysis however, several restrictions were imposed e. g. intermolecular O-O distance was kept fixed at $2.752 \AA$ (Vide Takamuku et al, 2004). Further for 2-propanol, the authors, being more interested in intermolecular correlations, did not extract molecular parameters, rather estimated them from those of liquid ethanol obtained from neutron diffraction (Tanaka et al, 1984). Recently, neutron diffraction experiments were carried out on deuterated liquid 1- and 2-propanols where the authors have used reactor data (Sahoo et al, 2008, 2010). The authors however claim that they have used modified method on conformational analysis than a direct fitting of high-q data. In literature no other neutron data on liquid 1- propanol is however available. These neutron diffraction studies by Sahoo et al, $(2008,2010)$ show the conformational difference in 1- and 2-propanols in liquid state at RT quite clearly and it appears that the molecular structures in liquid phase at RT are more or less identical with those in crystalline and gaseous phases. Since the conformational analyses reported by Sahoo et al appear quite convincing, in following paragraphs, some aspects of their method and results discussed.

\subsection{Neutron data and their analysis}

The neutron scattering experiments on deuteratred liquid propanol samples ( $99.8 \%$ pure) at RT carried out on Hi-Q diffractometer at Dhruva, Bhabha Atomic Research Centre (BARC, India) yielded raw data which have undergone a series of corrections using conventional procedures (Egelstaff, 1987). The corrected neutron cross-section $(\mathrm{do} / \mathrm{d} \Omega$ ) data were then extrapolated in the region $0 \leq \mathrm{q} \leq 0.3 \AA^{-1}$ and were normalized (on high-q as well) such that graphical extrapolation to $\mathrm{q} \rightarrow 0$ limit yields a correct isothermal compressibility of the liquid. The cross-section data are shown in Fig. 1 for both propanols.

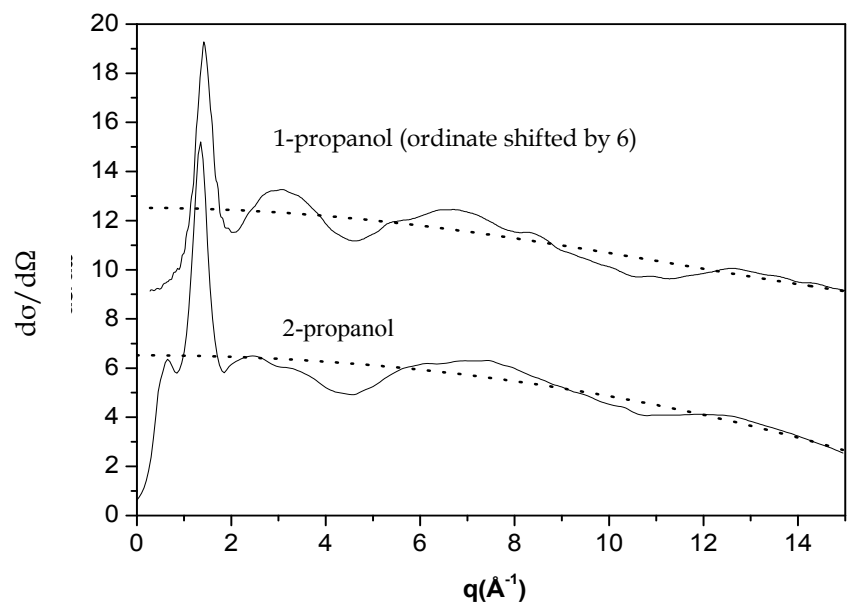

Fig. 1. do/d $\Omega$ vs. q for liquid D-1-and 2-propanols at RT; - corrected experimental data, -self term

In 2-propanol, data shows a strong pre-peak at a scattering vector $\mathrm{q} \sim 0.7 \AA^{-1}$ similar to one obtained in earlier Howells et al TOF, neutron data (Zetterström et al, 1991, 1994) and also in 
recent $x$-ray data (Takamuku et al, 2002). For 1-propanol, however, there is no significant pre-peak at a scattering vector $\mathrm{q} \sim 0.7 \AA^{-1}$ similar to earlier x-ray data (Mikusinska-Planner, 1977) though in recent $x$-ray data there is a weak pre-peak at $q \sim 0.7 \AA^{-1}$ (Takamuku et al, 2004). The cross- section data can be separated into "self" and "interference" terms,

$$
\mathrm{d} \sigma /\left.\mathrm{d} \Omega\right|_{\text {expt }}=\mathrm{d} \sigma /\left.\mathrm{d} \Omega\right|_{\text {self }}+\mathrm{d} \sigma /\left.\mathrm{d} \Omega\right|_{\text {int }}
$$

$\mathrm{do} /\left.\mathrm{d} \Omega\right|_{\text {int }}$ term oscillates and goes to zero at high $\mathrm{q}, \mathrm{d \sigma} /\left.\mathrm{d} \Omega\right|_{\text {expt }}$ is represented by appropriate self-scattering term at high q. The cross-section data has a "fall-off" feature at high $\mathrm{q}$ and this is due to interaction of incident neutrons with the vibrating scattering sites (deuterium atoms in particular for alcohols). This inelasticity effect modifies the selfscattering term and for alcohols this modification can be represented by a term involving two inelasticity parameters (Montague \& Dore, 1986; Champeney et al, 1986; Sahoo et al, 2008, 2010).

Thus,

$$
\mathrm{d} \sigma /\left.\mathrm{d} \Omega\right|_{\text {self }}=\left[3 \mathrm{~b}_{\mathrm{c}}^{2}+\mathrm{b}_{\mathrm{o}}^{2}+8 \mathrm{~b}_{\mathrm{d}}^{2}+8 \sigma_{d}^{i} / 4 \pi\right]\left(1-a \mathrm{q}^{2}+b \mathrm{q}^{4}\right)
$$

where $\sigma_{D}{ }^{i}$ is the incoherent scattering cross-section for deuterium and $a, b$ are two inelasticity parameters. $b_{c}, b_{o}, b_{d}$ are coherent scattering lengths of carbon, oxygen and deuterium atoms respectively. The inelasticity parameters $a, b$ were estimated by $\chi^{2}$-fitting between the self scattering term and the experimental cross-section data at high-q values starting from $\mathrm{q} \approx 5.5-6.0 \AA^{-1}$ (vide Fig. 1$)$. The parameters a and $\mathrm{b}$ are respectively $(3.22 \pm$ $0.04) \times 10^{-3} \AA^{2} \&(4.05 \pm 0.30) \times 10^{-6} \AA^{4}$ for 1-propanol and $(1.56 \pm 0.04) \times 10^{-3} \AA^{2} \&(5.04 \pm 0.30)$ $\times 10^{-6} \AA^{4}$ for 2-propanol.

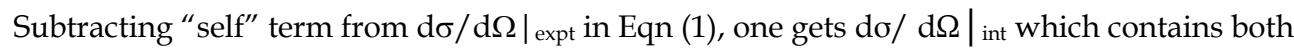
intra- and inter-molecular contributions. The total structure function, $\mathrm{H}(\mathrm{q})$ is defined as

$$
\mathrm{H}(\mathrm{q})=\mathrm{d} \sigma /\left.\mathrm{d} \Omega\right|_{\text {int }} /\left(\Sigma \mathrm{b}_{\alpha}\right)^{2}
$$

$\mathrm{H}(\mathrm{q})$ is separable into intra- and inter-molecular terms given by

$$
\mathrm{H}(\mathrm{q})=\mathrm{H}_{\mathrm{m}}(\mathrm{q})+\mathrm{H}_{\mathrm{d}}(\mathrm{q})
$$

where $\mathrm{H}_{\mathrm{m}}(\mathrm{q})=(\mathrm{d} \sigma / \mathrm{d} \Omega)_{\text {int }}$ intra $^{\text {in }} /\left(\sum \mathrm{b}_{\alpha}\right)^{2}$ and $\mathrm{H}_{\mathrm{d}}(\mathrm{q})=(\mathrm{d} \sigma / \mathrm{d} \Omega)_{\text {int }}$ inter $^{\text {in }} /\left(\sum \mathrm{b}_{\alpha}\right)^{2}$ :

The explicit expression for $\mathrm{H}_{\mathrm{m}}(\mathrm{q})$ is

$$
\mathrm{H}_{\mathrm{m}}(\mathrm{q})=\sum_{\alpha} \sum_{\alpha \neq \beta} \mathrm{b}_{\alpha} \mathrm{b}_{\beta} j_{0}\left(\mathrm{qr}_{\alpha \beta}\right) \exp \left(-\gamma_{\alpha \beta} \mathrm{q}^{2}\right) /\left(\sum_{\alpha} \mathrm{b}_{\alpha}\right)^{2}
$$

$\mathrm{r}_{\alpha \beta}$ being the mean distance between the sites $\alpha$ and $\beta$ and $\gamma_{\alpha \beta}$ is the mean square variation in the distance $\mathrm{r}_{\alpha \beta}$ with $\gamma_{\alpha \beta}=(1 / 2) \lambda_{0}{ }^{2} \mathrm{r}_{\alpha \beta}^{2}$, where $\lambda_{0}$ is taken to be a constant for all pairs (similar to Prins relation (Frenkel, 1955) ). For Debye-Waller terms same procedure was followed by other workers also (Tanaka et al, 1984). $\alpha$ and $\beta$ sum independently over 12 
atomic sites with $j_{0}(x)=\sin x / x$ is the zeroth order Spherical Bessel function. $H_{m}(q)$ is the intra interference term and gives information about the structure of the molecule, while $\mathrm{H}_{\mathrm{d}}(\mathrm{q})$ is the distinct structure function gives information about the inter-molecular or liquid structure. In terms of partial structure functions $\mathrm{H}_{\alpha \beta}(\mathrm{q}), \mathrm{H}_{\mathrm{d}}(\mathrm{q})$ is given by

$$
\mathrm{H}_{\mathrm{d}}(\mathrm{q})=\left(\sum_{\alpha} b_{\alpha}\right)^{-2} \sum_{\alpha} \sum_{\beta}\left(2-\delta_{\alpha \beta}\right) b_{\alpha} b_{\beta} \mathrm{H}_{\alpha \beta}(\mathrm{q})
$$

The inverse Fourier transform (IFT) of $\mathrm{H}_{\mathrm{d}}(\mathrm{q})$ gives the r-weighted neutron intermolecular correlation function $d(r)$ and radial distribution function $(\mathrm{RDF}), \mathrm{G}_{\mathrm{d}}(\mathrm{r})$ given by

$$
d(r)=\frac{2}{\pi} \int_{0}^{\infty} q H_{d}(q) \sin (q r) d q
$$

and

$$
\mathrm{G}_{d}(r)=1+d(r) / 4 \pi \rho r,
$$

where, $\rho$ is the liquid density. $G_{d}(r)$ is related to the partial pair distribution functions, $g_{\alpha \beta}(r)$ given by

$$
\mathrm{G}_{d}(r)=\left(\sum_{\alpha} b_{\alpha}\right)^{-2} \sum_{\alpha} \sum_{\beta}\left(2-\delta_{\alpha \beta}\right) b_{\alpha} b_{\beta} g_{\alpha \beta}(r)
$$

With

$$
g_{\alpha \beta}(r)=1+\frac{1}{2 \pi^{2} \rho r} \int_{0}^{\alpha} q H_{\alpha \beta}(q) \sin (q r) d q
$$

\subsection{Modified molecular conformation analysis}

In liquid alcohols, the effects of intermolecular hydrogen bonding persist at high q (Narten \& Habenchuss, 1984) and as a result $\mathrm{H}_{\mathrm{d}}(\mathrm{q})$ continues to exhibit oscillatory behaviour, positive and negative over $\mathrm{H}_{\mathrm{m}}(\mathrm{q})$. The function $\mathrm{H}_{\mathrm{d}}(\mathrm{q})$ however, tends to vanish more rapidly than the function $\mathrm{H}_{\mathrm{m}}(\mathrm{q})$ and so $\mathrm{H}(\mathrm{q})$ oscillates around $\mathrm{H}_{\mathrm{m}}(\mathrm{q})$ and tends to equalize with $\mathrm{H}_{\mathrm{m}}(\mathrm{q})$ at large $\mathrm{q}$. This means that for $\mathrm{q}$ greater than some $\mathrm{q}_{\mathrm{min}}$, the experimental total structure function $\mathrm{H}(\mathrm{q})$ comes primarily from intramolecular part. Assuming a model of the molecule from gas phase electron diffraction analysis (Abdel Aziz \& Rogowski, 1964) one can find the atom-atom distances for relevant analysis in liquid phase.

One can find $\mathrm{H}_{\mathrm{m}}(\mathrm{q})$ and fit $\mathrm{q} \mathrm{H}_{\mathrm{m}}(\mathrm{q})$ to experimental $\mathrm{qH}(\mathrm{q})$ for $\mathrm{q}>\mathrm{q}_{\min }$ by a $\chi^{2}$ fitting procedure and refine the distances and angles. One then subtract $\mathrm{H}_{\mathrm{m}}(\mathrm{q})$ from experimental $\mathrm{H}(\mathrm{q})$ in Eqn. (4) to obtain the first estimate of $\mathrm{H}_{\mathrm{d}}(\mathrm{q})$. The IFT of $\mathrm{H}_{\mathrm{d}}(\mathrm{q})$ yields intermolecular radial distribution function $\mathrm{G}_{\mathrm{d}}(\mathrm{r})$ by Eqn.(6a \& b ). Due to limited q-range ( $\mathrm{q}_{\max }$ ) available in the experiment, a modification function, $W(q)=\sin \left(q \pi / q_{\max }\right) /\left(q \pi / q_{\max }\right)$ (Champeney et al, $1986)$ is used in the IFT. Further, one chooses $q_{\max }$ such that $G_{d}(r=0)$ is almost zero which means that the contribution of the integral in Eqn. (6a) beyond $q=q_{\max }$ is almost zero. Again, the function $\mathrm{G}_{\mathrm{d}}(\mathrm{r})$ is expected to be zero in the range $0 \leq r \leq r_{0}$ where $r_{0}$ is about $1.5 \AA$ because 
the intermolecular distance cannot be less than this value. Setting $G_{d}(r)=0$ for this region a FT of the remaining $\mathrm{G}_{\mathrm{d}}(\mathrm{r})$ function would yield a new $\mathrm{qH}_{\mathrm{d}}(\mathrm{q})$. Subtracting this $\mathrm{qH}_{\mathrm{d}}(\mathrm{q})$ from experimental $\mathrm{qH}(\mathrm{q})$ one obtains the corrected $\mathrm{qH}_{\mathrm{m}}(\mathrm{q})$ function. The difference between the corrected $\mathrm{qH}_{\mathrm{m}}(\mathrm{q})$ and original $\mathrm{qH}_{\mathrm{m}}(\mathrm{q})$ is generally small. Varying molecular parameters, the subsequent iteration procedure gives the best fitting to this corrected function. A $\chi^{2}$ fitting is used for the whole range of $q$ data in steps of $0.01 \AA^{-1}$. This modified technique of finding molecular conformation of big molecules like alcohols somewhat resembles the method used by Bertagnolli (Bertagnolli et al, 1976) for neutron data analysis of liquid acetonitrile.

The schematic models chosen from the crystalline and gaseous phases are shown in Fig. 2. The molecules have 12 scattering sites and considering the symmetry of the structure one can minimize the number of parameters to describe the conformation. $\mathrm{C}_{1} \mathrm{C}_{2}$ is assumed in the $\mathrm{X}-\mathrm{Z}$ plane and $\mathrm{C}_{1} \mathrm{O}$ along the $\mathrm{Z}$-axis. The number of parameters are minimized by assuming all $C C$ and $C D$ distances equal. In 2-propanol the coordinates of $C_{3}$ and $D$ are obtained by $120^{\circ}$ and $240^{\circ}$ rotations of the $C_{2}$ coordinates about Z-axis respectively. Denoting by $\mathrm{D}_{1}$ the hydroxyl deuterium, three rotation angles $\phi_{\mathrm{OD}}, \phi_{1}, \phi_{2}$ and in addition to $\angle \mathrm{C}_{1} \mathrm{OD}_{1}$ angle and three internal distances $\mathrm{r}_{\mathrm{CC}}, \mathrm{r}_{\mathrm{CD}}$ and $\mathrm{r}_{\mathrm{OD}}$ are treated as variable parameters while the methyl backbones are assumed to have tetrahedral geometry with tilt angle of $\mathrm{C}_{1} \mathrm{O}$ relative to the methyl groups assumed zero. In 1-propanol the coordinates of $\mathrm{C}_{3}$ lie in X-Z plane. Here also three rotation angles $\phi_{1}, \phi_{2}, \phi_{3}$ in addition to $\angle \mathrm{C}_{1} \mathrm{OD}_{1}$ are treated as variable parameters and so also the $\mathrm{r}_{\mathrm{CC}}, \mathrm{r}_{\mathrm{CD}}$ and $\mathrm{r}_{\mathrm{OD}}$ parameters. The tilt angle of the methyl group is assumed zero, as in gas (Abdel Aziz \& Rogowski, 1964) and liquid ( $\mathrm{x}$ ray) (Takamuku et al , 2004) works. It is also to be noted that free rotations about $\mathrm{C}_{1} \mathrm{C}_{2}$ line would generate 'gauche' and 'trans' like conformations and the analysis takes care of these possibilities as well.
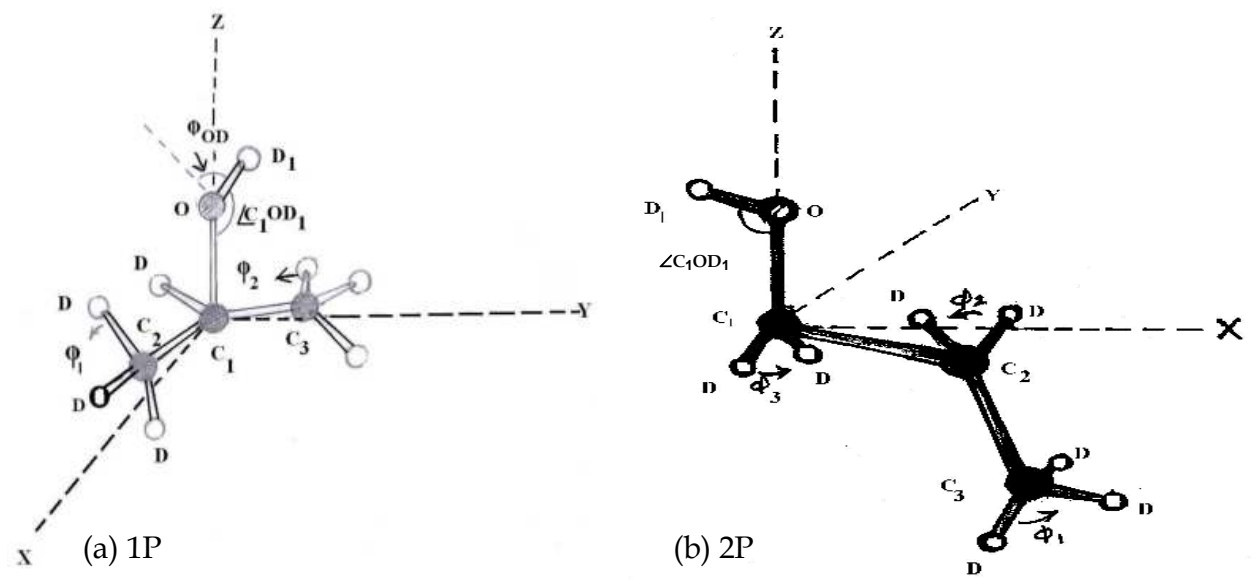

Fig. 2. Assumed models of molecules

\subsection{Results}

The fitted curves are shown in Figs. (3) and (4) and molecular parameters are listed in Table 2 together with results from other works. The Debye-Waller constant $\lambda_{0}$ were $3.84 \times 10^{-2} \AA^{-1}$ 

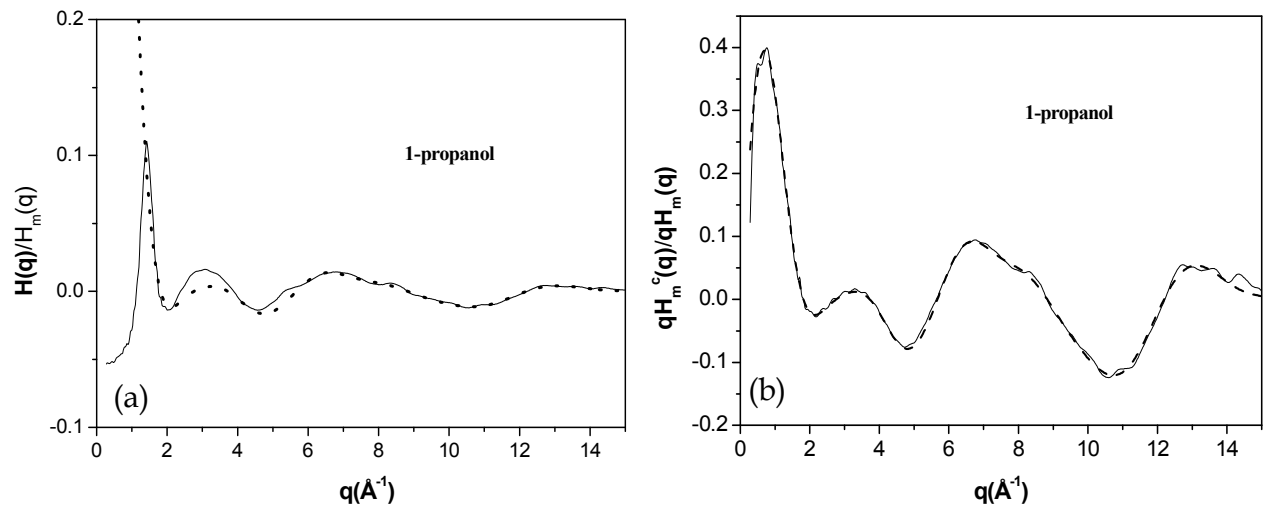

Fig. 3. 1P: (a) Structure function, $\mathrm{H}(\mathrm{q}) / \mathrm{H}_{\mathrm{m}}(\mathrm{q})$ vs $\mathrm{q}$ : - - - $-\mathrm{H}_{\mathrm{m}}(\mathrm{q}),-\mathrm{H}(\mathrm{q})$ (Exptl.). (b) $\mathrm{qH}$ (q) \& $\mathrm{qH}_{\mathrm{m}}^{\mathrm{c}}(\mathrm{q})$ vs q: - - $-\mathrm{qH}(\mathrm{q})$, $\mathrm{H}_{\mathrm{m}}^{\mathrm{c}}(\mathrm{q})$
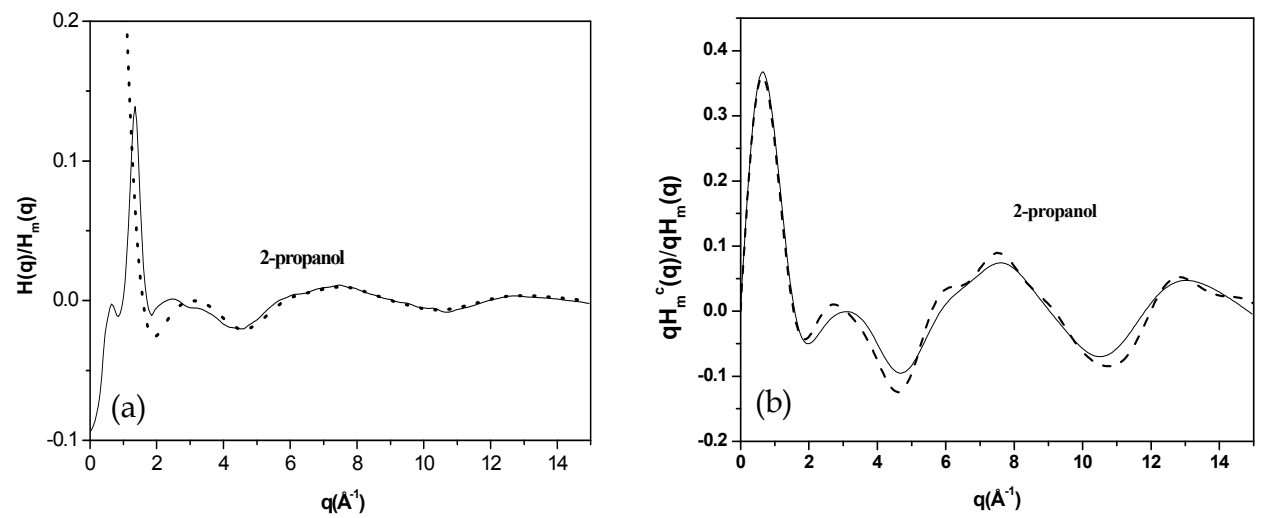

Fig. 4. 2P: (a) Structure function, $\mathrm{H}(\mathrm{q}) / \mathrm{H}_{\mathrm{m}}(\mathrm{q})$ vs q: - - - - $\mathrm{H}_{\mathrm{m}}(\mathrm{q})$, - H(q) (Exptl.). (b) $\mathrm{qH}_{\mathrm{m}}(\mathrm{q})$ \& $\mathrm{qH}_{\mathrm{m}}{ }^{\mathrm{c}}(\mathrm{q})$ vs q: - - $-\mathrm{qH}(\mathrm{q})$, $\mathrm{H}_{\mathrm{m}}{ }^{\mathrm{c}}(\mathrm{q})$

and $5.53 \times 10^{-2} \AA^{-1}$ for 1 - and 2-propanols respectively while the agreement factors, $\chi^{2}$ were respectively $1.35 \times 10^{-5}$ and $2.56 \times 10^{-5}$. In 2-propanol molecule, $\mathrm{r}_{\mathrm{CC}}$ appears to be little bit more and $\mathrm{r}_{\mathrm{CO}}$ to be somewhat less but these are not unreasonable if compared with Abdel Aziz \& Rogowski's electron diffraction work (1964) for $\mathrm{r}_{\mathrm{CC}}$ and Howells et al's neutron work(Zetterström et al, 1991) for $\mathrm{r}_{\mathrm{CO}}$. The $\mathrm{r}_{\mathrm{CO}}$ parameter in Howells et al's works was considerably less compared to those for other works (x-ray \& electron diffraction). Also in Howells et al's works both $\mathrm{r}_{\mathrm{OD}}$ and angle $\mathrm{C}_{1} \mathrm{OD}_{1}$ were abnormally low though their TOF neutron data were extended to as high as $30 \AA^{-1}$. The molecular conformation is however somewhat spherical in both Howells et al and Sahoo et al's neutron works. In 1-propanol molecule, $\mathrm{r}_{\mathrm{CC}}$ parameter appears to be a little bit less compared to other works. The other parameters are all reasonable. There is however no other neutron diffraction work available in the literature. Anyway, for a large molecule like propanol in liquid state these variations in molecular parameters are not unexpected and differences in $r_{\mathrm{CC}}$ and $\mathrm{r}_{\mathrm{CO}}$ values in two propanols might also result from large conformational differences. What is, however, 
The Molecular Conformations and Intermolecular Correlations in

\begin{tabular}{|c|c|c|c|c|c|c|c|c|c|}
\hline \multirow{2}{*}{$\begin{array}{l}\text { Molecular } \\
\text { Parameters }\end{array}$} & \multicolumn{2}{|c|}{ Neutrons, Reactor } & \multicolumn{2}{|c|}{ Neutrons, TOF } & \multicolumn{2}{|c|}{ X-rays } & \multicolumn{2}{|c|}{$\begin{array}{l}\text { Electron } \\
\text { Diff.(gas) }\end{array}$} & \multirow{2}{*}{\begin{tabular}{|l} 
MD \\
$1 \mathrm{P}$
\end{tabular}} \\
\hline & $2 \mathrm{P}$ & $1 \mathrm{P}$ & DALS & $2 \mathrm{P}, \mathrm{LAD}$ & $2 \mathrm{P}$ & $1 \mathrm{P}$ & $2 P$ & $1 \mathrm{P}$ & \\
\hline $\mathrm{r}_{\mathrm{CC}}(\AA)$ & $1.578 \pm 0.002$ & $1.477 \pm 0.003$ & $1.51 \pm 0.02$ & $1.543 \pm 0.004$ & 1.526 & 1.520 & $1.55-$ & 1.54 & 1.53 \\
\hline $\mathrm{r}_{\mathrm{CO}}(\AA)$ & $1.258 \pm 0.007$ & $1.443 \pm 0.012$ & $1.37 \pm 0.03$ & $1.340 \pm 0.03$ & 1.430 & 1.420 & $\begin{array}{l}1.56 \\
1.40\end{array}$ & 1.41 & 1.43 \\
\hline $\mathrm{r}_{\mathrm{CD}}(\AA)$ & $1.046 \pm 0.001$ & $1.053 \pm 0.002$ & $1.09 \pm 0.01$ & $1.109 \pm 0.007$ & 1.114 & 1.110 & 1.09 & 1.09 & - \\
\hline $\mathrm{rOD}_{\mathrm{O}}(\AA)$ & $1.029 \pm 0.0009$ & $0.986 \pm 0.010$ & $0.75 \pm 0.05$ & $0.876 \pm 0.025$ & 0.965 & 0.940 & 0.937 & 0.937 & 0.945 \\
\hline$\angle \mathrm{C}_{1} \mathrm{OD}_{1}\left({ }^{\circ}\right)$ & $110.52 \pm 0.7$ & $110.41 \pm 0.72$ & $76.41 \pm 3$ & $82.6 \pm 6.8$ & 125 & 108.5 & 105.9 & 105.9 & 108.5 \\
\hline$\phi_{1}\left(^{\circ}\right)$ & $-58.00 \pm 0.5$ & $14.03 \pm 0.03$ & $\phi_{1}=\phi_{2}$ & $\phi_{1}=\phi_{2}$ & - & - & - & - & - \\
\hline$\phi_{2}\left(^{\circ}\right)$ & $36.14 \pm 0.9$ & $0.86 \pm 0.03$ & $47.0 \pm 4$ & $-14.4 \pm 5.5$ & - & - & - & - & - \\
\hline$\phi_{3}\left(^{\circ}\right) / \phi_{\mathrm{OD}}\left({ }^{\circ}\right)$ & $-44.47 \pm 2.0$ & $7.2 \pm 0.03$ & $-15 \pm 2$ & 0 (fixed) & - & - & - & - & - \\
\hline
\end{tabular}

Table 2. Molecular parameters for propanols at RT
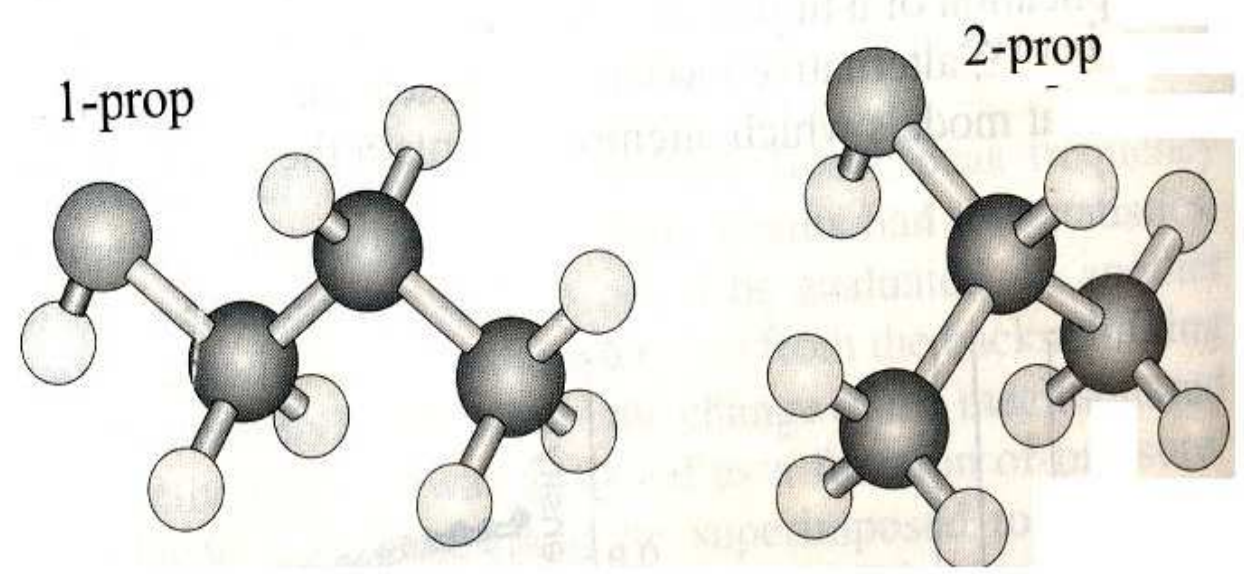

Fig. 5. Conformations of propanols.

important to note here is that the molecular conformation in 1-propanol is considerably elongated more like 'trans' which is also different from recent $\mathrm{x}$-ray result (Takamuku et al, 2004). This difference is probably due to the fact that in $x$-ray work the positions of hydrogen atoms can not be obtained accurately. It is however to be noted that the earlier $\mathrm{x}$ - 
ray diffraction on liquid 1-propanol (Mikusinska-Planner, 1977) yielded nearly a 'trans' conformation. The molecular conformation of 2-ropanol is almost spherical and in liquid state at RT, two propanols have very different conformations more like that in crystalline solid (Talon et al, 2002). The deduced conformations are shown in Fig. 5. The conformations obtained via neutron data analysis are expected to be more convincing than those obtained through x-ray data analysis. The molecular structural differences result in the differences in intermolecular potential energy functions and radial distribution functions which could lead to significant differences in basic thermodynamic and other properties.

\section{Molecular association studies}

The hydrogen bonded molecular liquid alcohols (e.g. t-butanol) have very distinct type of intermolecular correlations compared to the corresponding non-hydrogen-bonded molecular liquids (e. g. neopentane) (Sarkar et al, 2000). In normal molecular liquids, the orientation correlations determine the liquid structure and properties (both thermodynamic and transport) of the system. In H-bonded molecular liquids the existence of hydrogen bonds strongly affects the static and dynamic properties of the liquids. The liquid structure is enormously different for the two cases and these structural distinctions are reflected in many physical and some chemical properties of the substances (Pauling, 1967). These changes are likely in the light of the fact that H-bonding may alter the mass, size, shape and arrangement of atoms, as well as the electronic structure of the functional groups resulting in the polymerization or formation of cluster in the liquid state. As a matter of fact, the degree of structural complexity increases as the number of atoms participating in the $\mathrm{H}$ bonding increases. A full understanding of the structural and dynamical properties of these liquids has not been achieved even in ambient conditions. It is however true that the characteristic features of liquid structure and correlations in H-bonded liquids are distinctly exhibited in structure function (presence of pre-peak at q $0.7 \AA^{-1}$ )and very clear in real space distribution functions obtained by FT of the q-space functions. The lack of long-range order and complexity of intermolecular interactions, however, turn the analysis a complex task except for the simplest molecular systems (e. g. water etc.). The computer simulations (both MC and MD) have been very useful (Jogensen, 1986 ; Svishchev \& Kusalik, 1993) but the results often differ with results from diffraction experiments, the reason possibly being the inability of the simulation methods to incorporate the connectivity effects in the intermolecular interactions, so important in H-bonded liquid alcohols (Sum \& Sandler, 2000). However, with the advantage of powerful computational tools and modeling algorithms, it is now a realistic possibility to conduct comprehensive 3D models of these complex systems that are consistent with available experimental data (Soper, 1996). Alternatively, a careful analysis via geometrical modeling can also yield satisfactory results in several cases with relatively large molecules (Magini et al, 1982; Sarkar \& Joarder, 1993, 1994). Similar efforts have been also made with x-ray data earlier for liquid t-butanol and 1propanol (Karmakar et al, 1995; Mikusinska-Planner, 1977) and in recent past for liquid 1and 2-propanols in aqueous solutions (Takamuku et al, 2002, 2004). In view of large conformational differences in liquid 1- and 2-propanols the investigation of their average molecular associations in liquid state is a quite interesting. The investigation using neutron diffraction data reported in recent past (Sahoo et al, 2009, 2010) is briefly described in the following paragraphs. 


\subsection{Theory of regular molecular association or cluster}

(Sarkar \& Joarder, 1993, 1994)

The theory is based on a few simplified assumptions:

i. The liquid, on average, is considered to be an aggregate of small clusters of specific size composed of several molecules.

ii. The molecules in different clusters are orientationally uncorrelated.

Now, the general expression for the total structure function $H$ (q) devoid of self term is given by

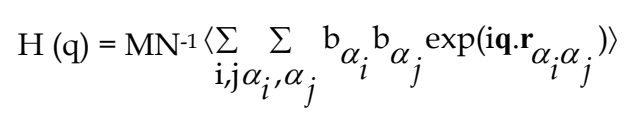

Where $\mathrm{M}=\left(\sum b_{\alpha_{i}}\right)^{-2}$, the $<\ldots>$ bracket denotes an ensemble average, $\mathrm{i}$ and $\mathrm{j}$ label the molecules in the liquid, $\alpha_{\mathrm{i}}$, the $\alpha$ th atom in the ith molecule, $\mathrm{r}_{\alpha \mathrm{i}, \alpha \mathrm{j}}$ the distance between the atoms $\alpha_{\mathrm{i}}$ and $\alpha_{\mathrm{j}}, \mathrm{b}_{\mathrm{\alpha i}}$, the scattering length (in neutron case) or q-dependent atomic scattering factor (in x-ray case) of the atom $\alpha_{i}$ and the summation extends over all the scatterers in $\mathrm{N}$ molecules in the liquid.

Considering the assumption (i), on the right hand side of Eqn.(8), the separation of the contribution of atom pair terms within the clusters, called the cluster structure function $\mathrm{H}_{\mathrm{c}} \mathrm{m}(\mathrm{q})$, from the inter-cluster contribution is permitted in general. We have then

$$
\mathrm{H}(\mathrm{q})=\mathrm{H}_{\mathrm{c}}^{\mathrm{m}}(\mathrm{q})+\mathrm{MN}^{-1}\left\langle\sum_{\mu \neq \nu 1} \sum_{1_{\mu}, 1_{v}} \sum_{\alpha_{1_{\mu}}, \alpha_{1_{v}}} b_{\alpha_{1_{\mu}}} b_{\alpha_{1_{v}}} \exp \left(\mathrm{iqr}_{\alpha_{1_{\mu}} \alpha_{1_{v}}}\right)\right\rangle
$$

where

$$
\mathrm{H}_{\mathrm{c}}^{\mathrm{m}}(\mathrm{q})=\mathrm{MN}^{-1}\left\langle\sum_{\mu} \sum_{1_{\mu}, 1_{\mu^{\prime}} \alpha_{1_{\mu}}, \alpha_{1 \mu^{\prime}}} b_{\alpha_{1} \mu^{\prime}} b_{\alpha_{1 \mu^{\prime}}} \exp \left(\mathrm{iqr}_{\alpha_{1_{\mu}} \alpha_{1 \mu^{\prime}}}\right)\right\rangle
$$

1 and $l^{\prime}$ label molecules within a given cluster, and $1_{\mu}$, the l-th molecule in the cluster $\mu$.

Let us use $r_{c_{\mu_{\mu}} 1_{v}}$ to denote the vector distance from the centre of the molecule $l_{\mu}$ to that of the molecule $l_{v}$ such that,

$$
\mathrm{r}_{\alpha_{1_{\mu}} \alpha_{1_{v}}}=\mathrm{r}_{\mathrm{c}_{1_{\mu} 1_{v}}}-\mathrm{r}_{\mathrm{c} \alpha_{1_{\mu}}}-\mathrm{r}_{\mathrm{c} \alpha_{1_{v}}}
$$

where $\mathrm{r}_{\mathrm{c} \alpha_{1_{\mu}}}$ is the vector distance from the centre of the molecule $1_{\mu}$ to its $\alpha$-th nucleus within the cluster $\mu$. Eqn.(9) can then be written as

$$
\mathrm{H}(\mathrm{q})=\mathrm{H}_{\mathrm{c}}^{\mathrm{m}}(\mathrm{q})+\mathrm{MN}^{-1}\left\langle\sum_{\mu \neq v} \sum_{1_{\mu}, 1_{v}} \exp \left[\left(\mathrm{iq}\left(\mathrm{r}_{c_{1_{\mu}, 1_{v}}}\right)\right] \times \sum_{\alpha_{1_{\mu}}, \alpha_{1_{v}}} b_{\alpha_{1_{\mu}}} b_{\alpha_{1_{v}}} \exp \left[\mathrm{iq}\left(-\mathrm{r}_{c \alpha_{1_{\mu}}}-\mathrm{r}_{c \alpha_{1_{v}}}\right)\right]\right\rangle\right.
$$

Eqn.(12) is quite general, the first term can be calculated for a given cluster of molecules but the second term can not be simplified without making some assumption because the 
orientation of the $1_{\mu}$ molecule (i.e. $r_{c \alpha_{1}}$ ) depends on that of the $1_{v}$ molecule (i.e. $r_{c \alpha_{1}}$ ) and on their separation $\left(\mathrm{r}_{c_{l_{\mu} l_{v}}}\right)$. If $\mathrm{r}_{\mathrm{c}_{l_{\mu} l_{v}}}$ is large, $\mathrm{r}_{c \alpha_{1_{\mu}}}$ and $\mathrm{r}_{\mathrm{c} \alpha_{1_{v}}}$ are statistically independent. However, an important contribution to $\mathrm{H}(\mathrm{q})$ of interest comes from short $\mathrm{r}_{\mathrm{c}_{1_{\mu} \mathrm{l}_{v}}}$ where orientations are not statistically independent. For this reason, the assumption (ii) is made and then $\mathrm{r}_{\mathrm{c} \alpha_{1_{\mu}}}$, $\mathrm{r}_{\mathrm{c} \alpha_{1_{v}}}$ and $\mathrm{r}_{\mathrm{c}_{1_{\mu} l_{v}}}$ all are taken to be statistically independent. One can now simplify Eqn. (12).

Since

$$
<\exp (\text { iq.r) })>=<\exp (- \text { iq.r) })>
$$

Eqn.(12) becomes

$$
\mathrm{H}(\mathrm{q})=\mathrm{H}_{\mathrm{c}}^{\mathrm{m}}(\mathrm{q})+\mathrm{MN}^{-1}\left\langle\sum_{\mu \neq v} \sum_{1_{\mu}, 1_{v}} \exp \left(\mathbf{i q} \cdot \mathbf{r}_{\mathrm{c}_{1_{\mu} 1_{v}}}\right)\right\rangle \times\left[\sum_{\alpha} \mathrm{b}_{\alpha}\left\langle\exp \left(\mathbf{i q} \cdot \mathbf{r}_{\mathrm{c} \alpha}\right)\right\rangle\right]^{2}
$$

In terms of form factor representing completely uncorrelated orientational configuration between molecules one writes

$$
\mathrm{F}_{2 \mathrm{u}}(\mathrm{q})=\mathrm{M}\left[\Sigma \mathrm{b}_{\alpha}<\exp \left(\mathrm{iq} \cdot \mathbf{r}_{\mathrm{c} \alpha}\right)>\right]^{2},
$$

where $r_{c \alpha}$ is the vector distance from the centre of a molecule to its $\alpha$-th nucleus.

If one now considers the case of a system consisting of identical clusters, each of which is composed of $\mathrm{N}_{\mathrm{c}}$ molecules. Then from Eqn.(13) one can write

$$
H(q)=H_{c}^{m}(q)+F_{2 u}(q) N^{-1}\left[\left\langle\sum_{i \neq j} \exp \left(i q \cdot r_{c_{i j}}\right)\right\rangle-\frac{N}{N_{C}}\left\langle\sum_{l \neq 1^{\prime}} \exp \left(i q \cdot r_{c_{11}}\right)\right\rangle\right]
$$

or,

$$
H(q)=H_{c}^{m}(q)+F_{2 u}(q)\left[N^{-1}\left\langle\sum_{i \neq j} \exp \left(i q \cdot r_{c_{i j}}\right)\right\rangle+1-N_{c}^{-1}\left\langle\sum_{1 \neq 1^{\prime}} \exp \left(i q \cdot r_{c_{11}}\right)\right\rangle-1\right]
$$

Thus, one writes $\mathrm{H}(\mathrm{q})$ in the form,

$$
H(q)=H_{c} m(q)+F_{2 u}(q)\left[S_{c}(q)-f_{3}(q)-1\right]
$$

with

and

$$
\begin{aligned}
& S_{c}(q)=1+N^{-1}\left\langle\sum_{i \neq j} \exp \left(i q \cdot r_{c_{i j}}\right)\right\rangle \\
& f_{3}(q)=N_{c}^{-1}\left\langle\sum_{l \neq 1^{\prime}} \exp \left(i q \cdot r_{c_{1 l^{\prime}}}\right)\right\rangle
\end{aligned}
$$

Here, $S_{c}(q)$ is the molecular centre structure factor of the liquid and $f_{3}(q)$, a factor resulting from the molecular centre pairs within the cluster. 
Since there is no preferential orientation of the molecule with respect to the direction $q$, an orientation average may be evaluated and the one writes

$$
<\exp \left(\text { iq. } \mathbf{r}_{\mathrm{ij}}\right)>=\mathrm{j}_{0}\left(q \mathrm{r}_{\mathrm{ij}}\right)=\frac{\sin \left(\mathrm{qr}_{\mathrm{ij}}\right)}{q \mathrm{r}_{\mathrm{ij}}}
$$

Including 'Debye-Waller' factors in Eqns. (14), (16a) and (16b) one can write

$$
\begin{gathered}
F_{2 u}(q)=M\left[\sum_{\alpha} b_{\alpha} j_{0}\left(q_{c \alpha}\right) \exp \left(-l_{c \alpha}^{2} q^{2} / 2\right)\right]^{2} \\
S_{c}(q)=1+N^{-1} \sum_{i \neq j} j_{0}\left(q_{c_{i j}}\right) \exp \left(-1_{c_{i j}}^{2} q^{2} / 2\right) \\
f_{3}(q)=N_{c}^{-1} \sum_{l \neq 1^{\prime}} j_{0}\left(q_{c_{\text {III }}}\right) \exp \left(-1_{c_{11}}^{2} q^{2} / 2\right)
\end{gathered}
$$

The exponential factor, related to Debye-Waller factors, contains a $1_{\alpha \beta}$ parameter which is the root mean square deviation of the local instantaneous atom-atom separation distance $r_{\alpha \beta}$.

The cluster structure function $\mathrm{H}_{\mathrm{c}} \mathrm{m}(\mathrm{q})$ can be separated into the intra-molecular structure function $\mathrm{H}_{\mathrm{m}}(\mathrm{q})$ and the inter-molecular structure function $\mathrm{H}_{\mathrm{c}}(\mathrm{q})$ within a cluster.

Thus one writes,

$$
\mathrm{H}_{\mathrm{c}} \mathrm{m}(\mathrm{q})=\mathrm{H}_{\mathrm{m}}(\mathrm{q})+\mathrm{H}_{\mathrm{c}}(\mathrm{q})
$$

where,

$$
\begin{gathered}
\mathrm{H}_{\mathrm{m}}(\mathrm{q})=\mathrm{M} \sum_{\alpha} \sum_{\alpha \neq \beta} \mathrm{b}_{\alpha} \mathrm{b}_{\beta} \mathrm{j}_{0}\left(\mathrm{qr}_{\alpha \beta}\right) \exp \left(-\mathrm{l}_{\alpha \beta^{\prime}}^{2} \mathrm{q}^{2} / 2\right) \\
\mathrm{H}_{\mathrm{c}}(\mathrm{q})=\mathrm{N}_{\mathrm{c}}^{-1} \mathrm{M} \sum_{1 \neq 1^{\prime} \alpha, \beta} \sum_{\alpha_{1}} \mathrm{~b}_{\beta_{\beta^{\prime}} \mathrm{j}_{0}}\left(\mathrm{qr}_{\alpha_{1} \beta^{\prime} 1^{\prime}}\right) \exp \left(-\mathrm{l}_{\alpha_{1} \beta_{1}^{\prime}}^{2} \frac{\mathrm{q}^{2}}{2}\right)
\end{gathered}
$$

Eqn. (16) reduces to

$$
H(q)=H_{m}(q)+H_{c}(q)+F_{2 u}(q)\left[S_{c}(q)-f_{3}(q)-1\right]
$$

The second and third term in Eqn.(19) combine to form the conventional inter-molecular "distinct" structure factor $\mathrm{H}_{\mathrm{d}}(\mathrm{q})$. So finally one gets

$$
H(q)=H_{m}(q)+H_{d}(q)
$$

And

$$
H_{d}(q)=H_{c}(q)+F_{2 u}(q)\left[S_{c}(q)-f_{3}(q)-1\right]
$$

The second term in Eqn.(20 b), the inter-molecular contribution, goes to zero for large $q$ and one gets $\mathrm{H}_{\mathrm{d}}(\mathrm{q}) \rightarrow \mathrm{H}_{\mathrm{c}}(\mathrm{q})$, and this is very useful in identifying any average inter-molecular cluster present in the liquid. 


\subsection{Identifying the average molecular association or cluster from diffraction data}

The theory described above is used in this section to identify the presence of average molecular association or cluster in the two liquid propanols at RT using neutron diffraction data. The cluster parameters obtained for the most probable cluster are then used to generate the model $\mathrm{x}$-ray $\mathrm{H}(\mathrm{q})$ function and compared with available experimental $\mathrm{x}$-ray data. The good agreement obviously completes the identification of the most probable cluster present in liquid state. The method was earlier successfully applied to liquid methanol, ethanol, t-butanol etc. (Sarkar \& Joarder, 1993, 1994; Karmakar et al, 1995). The present application of the method to two propanols in liquid state at RT is to check if there is any significant differences in the nature of most probable cluster or association in them. This investigation is important in view of significant differences in molecular conformation and thermodynamic and other properties of these two isomeric liquids. Between the two, 2-propanol is conformationally simpler and easier to tackle so its associational analysis is reported first.

\section{(a) 2-propanol:}

The diffraction data of liquid 2-propanol (both neutron and x-ray (Sahoo et al, 2010; Takamuku et al, 2002) show pre-peak at $\mathrm{q} \sim 0.7-0.8 \AA^{-1}$ which is indicative of molecular association in liquid state. For a large molecule like 2-propanol the center structure factor of the liquid can be approximated by the PY single-site hard-sphere model (Karmakar et al, 1995) with a suitable core diameter. Two widely suggested probable molecular association models for alcohols are considered here namely, a tetramer linear chain (TLC) cluster (Magini et al, 1982) and an hexamer ring chain (HRC) cluster (Sarkar \& Joarder, 1993, 1994; Karmakar et al, 1995) of neighboring molecules for liquid 2-propanol at RT. The cluster models are shown in Fig. 6. Considering all O-D...O bonds coordinates of all atomic sites are calculated. For simplification $\mathrm{CD}_{3}(\equiv \mathrm{R})$ is taken as a single scattering unit following group scattering concept with appropriate scattering center and scattering length (Narten \& Habenchuss, 1984).
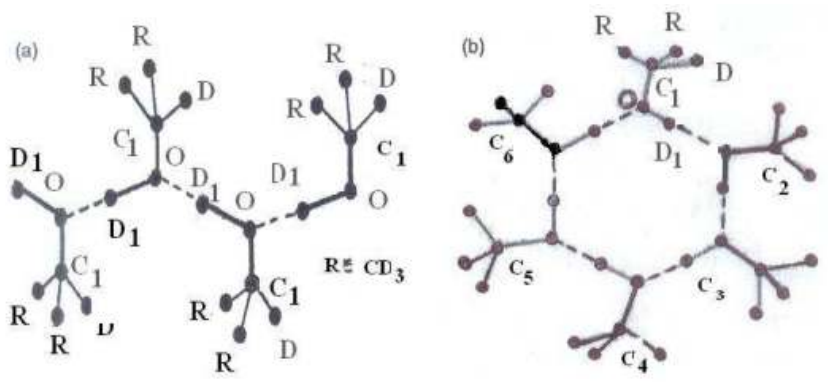

Fig. 6. Model clusters for 2-propanol: (a) Probable TLC structure, (b) Probable HRC structure.

The carbon atom denoted by $\mathrm{C}$ (vide Fig. 6) is taken to be centre of the bonded molecule. Varying the parameters like intermolecular $\mathrm{O}-\mathrm{O}$ distance and the orientation and rotation angles of all $\mathrm{C}^{\prime}$ s and $\mathrm{R}^{\prime} \mathrm{s}$ within the cluster one fits the model $\mathrm{qH}_{\mathrm{d}}(\mathrm{q})$ to experimental $\mathrm{qH}_{\mathrm{d}}(\mathrm{q})$ function by $\chi^{2}$ fitting programme. The fitted curves for these two models are shown in Fig. 7(a) and clearly the HRC model is far superior. The model total structure functions $\mathrm{H}(\mathrm{q})$ obtained from Eqn. (19) are also shown in Fig.7(b). The pre-peak in the experimental diffraction pattern, characteristic of chain or cluster is satisfactorily generated in the HRC model. The HRC model parameters are shown in Table 3. 
It is to be noted that hard core diameter $(4.45 \AA)$ and O-O distance parameter $(2.68 \AA$ for $\mathrm{HRC}$ model) are somewhat smaller than corresponding values for liquid $\mathrm{t}$-butanol (Nath et al, 2002). The O-O parameter is also less compared to $2.736 \AA$ from $\mathrm{x}$-ray data analysis (Takamuku et al, 2002). The smaller O-O distance associated with HRC structure might be attributed to the non-planar nature of hexameric rings which allows the neighbouring molecules to come closer. In x-ray work however, the number of $\mathrm{H}$-bonds per monomer was nearly 2 in agreement with HRC model. The intermolecular $G_{d}(r)$ obtained from $H_{d}(q)$ are shown in Fig. 8 for both models and HRC is again seen to be superior. Now using the parameters obtained from neutron data analysis, the model $\mathrm{H}(\mathrm{q})$ function for $x$-ray diffraction can be computed. In the process neutron scattering lengths are replaced by corresponding q-dependent $\mathrm{x}$ - ray atomic scattering factors. The HRC model result compare quite favorably with experimental x-ray H(q) data ( Fig. 9). As pointed out in by Sahoo et al (2010) much better agreement is possible if the cluster parameters are little bit adjusted. It is however to be noted here that the average molecular association extracted here is very different from the probable chain molecular association suggested in Takamuku et al's xray work (2002). In x-ray work authors suggested trimer molecular association in cis and trans form and assumed a continuum beyond nearest neighbours. This association

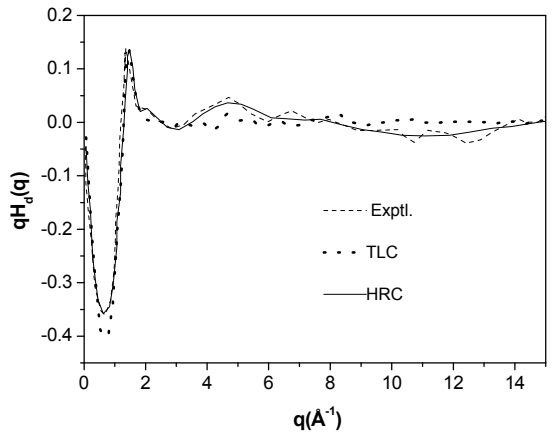

(a)

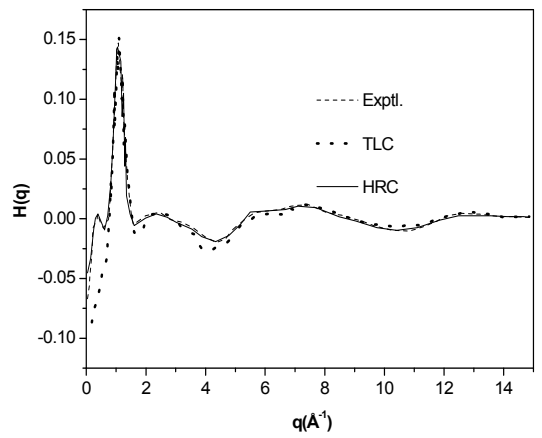

(b)

Fig. 7. (a). $\mathrm{qH}_{\mathrm{d}}(\mathrm{q})$ vs q of D-2-propanol, (b). H(q) vs q of D-2-propanol

was, however, not conclusive.

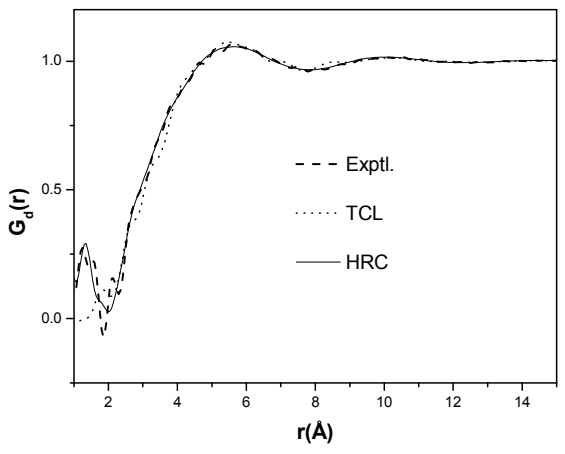

Fig. 8. $\mathrm{G}_{\mathrm{d}}(\mathrm{r})$ vs $\mathrm{r}$ of D-2-propanol 


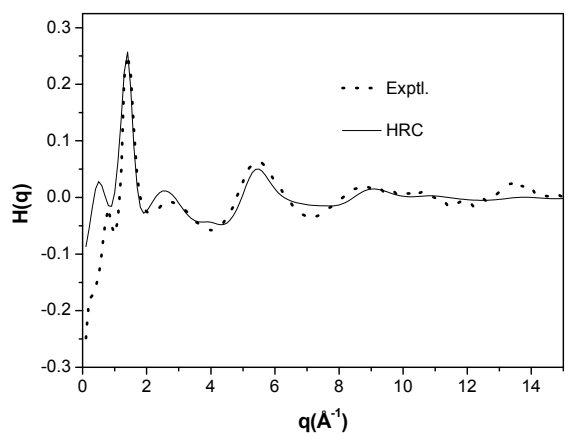

Fig. 9. 2-propanol (x-ray data): H(q) vs q

\begin{tabular}{|l|c|c|}
\hline $\begin{array}{l}\text { O-O } \\
\text { distance }\end{array}$ & $\begin{array}{l}\text { Rotational } \\
\text { angles(deg)of C's } \\
\text { about OD line }\end{array}$ & $\begin{array}{l}\text { Rotational } \\
\text { angles(deg) of R's } \\
\text { about CO line }\end{array}$ \\
\hline \multirow{5}{*}{$2.68 \AA ⿱ ㇒$} & $(\mathrm{C} 1) 180.14^{\circ}$ & (R1) $18.00^{\circ}$ \\
& (C2) $54.18^{\circ}$ & (R2) $-114.72^{\circ}$ \\
& (C3) $60.80^{\circ}$ & (R3) $-11.54^{\circ}$ \\
& (C4) $108.88^{\circ}$ & (R4) $86.28^{\circ}$ \\
& (C5) $28.92^{\circ}$ & (R5) $1.36^{\circ}$ \\
(C6) $17.00^{\circ}$ & (R6) $-11.64^{\circ}$ \\
\hline
\end{tabular}

Hardcore diameter, $\mathrm{o}=4.45 \AA$; Non-planer angle, $\delta=3^{\circ}$.

Table 3. HRC model parameters for 2-propanol

\section{(b) 1-propanol:}

Since 1-propanol in liquid state at RT has significantly different molecular conformation and properties, its molecular association in liquid state would be interesting. Further, the only neutron data available does not show any significant pre-peak like one for the earlier x-ray diffraction data (Mikusinska-Planner, 1977). The recent x-ray data (Takamuku et al, 2004) however shows a weak pre-peak at $\mathrm{q} \sim 0.7-0.8 \AA^{-1}$ but less prominent than one in 2-propanol data. The earlier $x$-ray diffraction study showed a preference for linear pentamer chain while the recent $x$-ray diffraction study pointed out a preference for linear trimer chain. Using neutron diffraction data Sahoo et al (2009) tested four model clusters namely, open chain winding 'trimer', 'tetramer', 'pentamer' and also HRC. The model clusters are shown in Fig.10 and in the calculation $\mathrm{CD}_{3}(\equiv \mathrm{R})$ and $\mathrm{CD}_{2}\left(\equiv \mathrm{R}_{1}\right)$ are considered as single scattering sites with appropriate location of scattering centre and scattering lengths to avoid insertion of many more parameters. This approximation, as pointed out by Sahoo et al (2009), would little affect the intermolecular contribution where, in general, larger distances are involved and also because all D's are symmetrically located with $C^{\prime}$ s in $\mathrm{CD}_{3}$ and $\mathrm{CD}_{2}$. This would also mean that when D's are treated separately flexible rotations of D's about corresponding C-C bonds would not contribute very differently to the intermolecular cluster structure function, $\mathrm{H}_{\mathrm{c}}(\mathrm{q})$ involving several molecules. Further the size of the molecule being large the centre structure can be approximated by PY single site hard sphere expression with appropriate core diameter and the centre located appropriately. 


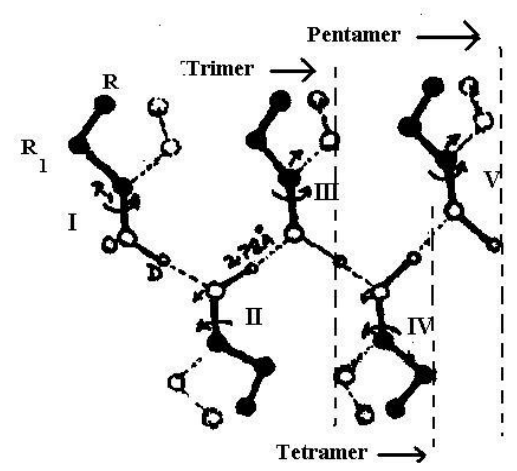

(a)

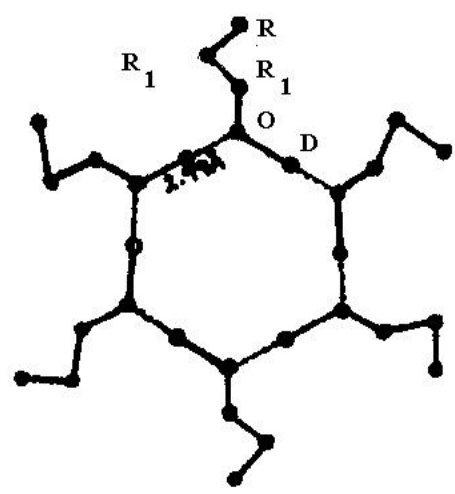

(b)

Fig. 10. Model clusters for 1P, (a) Probable trimer to pentamer structures. (b) Probable HRC structure.

Varying the parameters like the hard-core diameter, inter-molecular O-O distance and in the case of chain clusters the rotational angles of all $R_{1} R_{1} R$ and winding of the chain i.e. twist of $\mathrm{OR}_{1}$ 's etc. within a cluster and in the case of HRC, the rotational angles of all $R_{1} R_{1} R$ about OD axes and all twist angles of $R_{1} R$ about $R_{1} R_{1}$ within a cluster the model $q H_{d}(q)$ is fitted to experimental $\mathrm{qH}_{\mathrm{d}}(\mathrm{q})$ function by a $\chi^{2}$-fitting programme. The fitted curves are shown in Fig. 11(a) and (b). Though somewhat surprising (in view of large conformational differences) it is seen that HRC is too the most probable average molecular association in liquid 1-propanol at RT. This is seen to be true for $G_{d}(r)$ curve also (Fig. 12). The agreement with linear chain models is only so so.

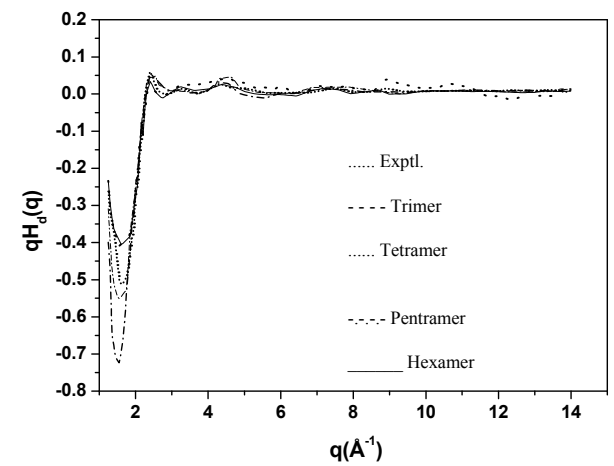

(a)

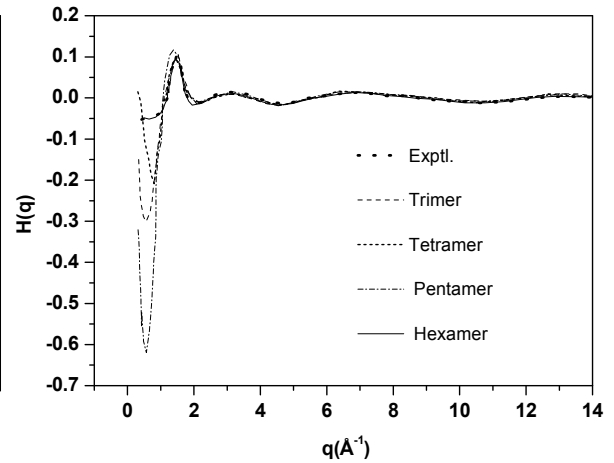

(b)

Fig. 11. (a). $\mathrm{qH}_{\mathrm{d}}(\mathrm{q})$ vs q of D-1-propanol, (b). H(q) vs q of D-1- propanol

The HRC model parameters are shown in Table 4 . The O-O distance parameter $(2.99 \AA)$ is somewhat larger compared to that for 2-propanol. Further it is also larger compared to those for x-ray data analysis (Takamuku et al, 2002) and MD work (Akiyama et al, 2004). This larger O-O distance would be probably due to the elongated conformation of 1-propanol molecule and the planar nature of the hexameric rings which might cause stretching on the 


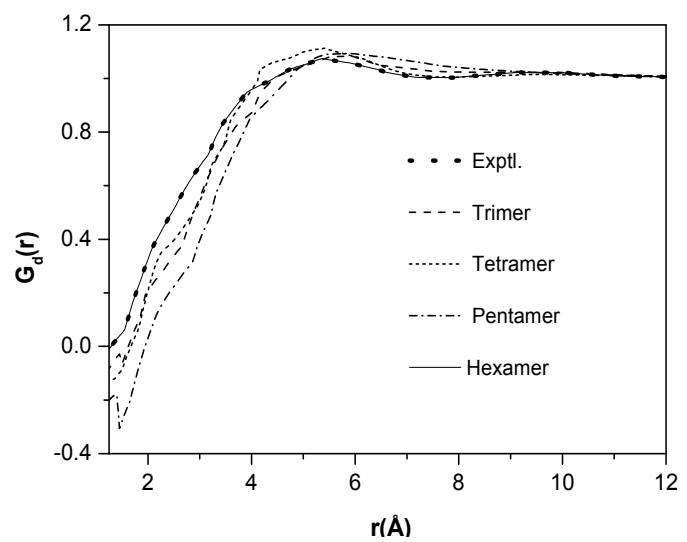

Fig. 12. $G_{d}(r)$ vs $r$ of D-1-propanol

\begin{tabular}{|l|l|l|}
\hline $\begin{array}{l}\text { O-O } \\
\text { distance }\end{array}$ & $\begin{array}{l}\text { Rotational } \\
\text { angles(deg)of } \\
\text { about OD line }\end{array}$ & $\begin{array}{l}\text { Rotational } \\
\text { angles(deg) of R's } \\
\text { about CO line }\end{array}$ \\
\hline & & (R1) $18.86^{\circ}$ \\
& (C1) $139.90^{\circ}$ & (R2) $334.24^{\circ}$ \\
& (C2) $48.62^{\circ}$ & (R3) $224.88^{\circ}$ \\
(C3) $51.38^{\circ}$ & (R4) $-17.86^{\circ}$ \\
& (C4) $134.24^{\circ}$ & (R5) $80.40^{\circ}$ \\
& (C5) $21.38^{\circ}$ & (R6) $18.82^{\circ}$ \\
\hline
\end{tabular}

Table 4. HRC model parameters for 1-propanol, Hardcore diameter, o=4.5

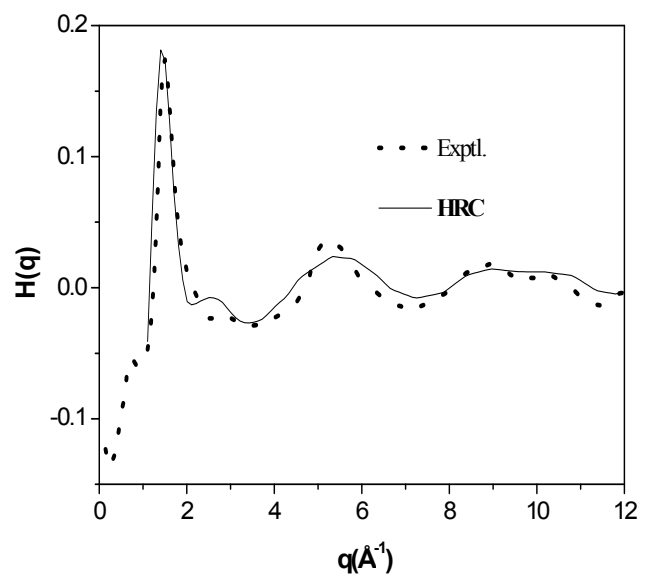

Fig. 13. H(q) vs. q for 1-propanol, (x-ray data) 
intermolecular H-bonding. Again, the x-ray H(q) function computed for HRC model using neutron HRC parameters show very reasonable agreement with experimental $x$-ray $H(q)$ data(Fig. 13). Much better agreement is however possible if the HRC parameters are little bit adjusted (Sahoo, 2011)

\subsection{The liquid structure, 1-propanol vs. 2-propanol}

In spite of large differences in molecular conformation and other properties the liquid structure is surprisingly similar in two propanols in liquid state at RT and these are most probably hexameric rings. Small but significant existence of other clusters are not ruled out but to show this, very careful examinations are obligatory. The earlier computer simulation studies on several liquid monohydric alcohols including 1-propanol (Jorgensen, 1986) suggested in support of winding linear chain configurations of several molecules and did so on the basic of atom-atom RDF peak locations but these were never conclusive. In 1propanol, in view of an elongated conformation, a linear chain as average structure could be a possibility but the present result is seen to be otherwise. The very careful recent other studies also show that the presence of hexameric rings as average molecular units is possible in liquid alcohol like methanol (Kastanov et al, 2005, Gonzalez et al, 2007).

Though the average molecular association is similar in two propanols in liquid state there are several differences. The 2-propanol hexamer is not exactly planer. The intermolecular O$\mathrm{O}$ distance is considerably less and most of the rotation angles for $\mathrm{R}^{\prime} \mathrm{s}$ about $\mathrm{CO}$ line are very different. This is not unlikely in view of large conformational differences of two propanols. These differences are also reflected in $\mathrm{G}_{\mathrm{d}}(\mathrm{r})$ curves (vide Figs. 8 \&12). In spite of apparent similarity there are minor differences in peak locations. It is also to be noted here that using the HRC model it is possible to evaluate the intermolecular pair distribution functions, namely, $g_{O O}(r), g_{O D}(r), g_{D D}(r)$ etc. from the experimental data (Sahoo et al, 2010; Sahoo, 2011). In Table 5 the locations of first and second peaks of these functions for two propanols in liquid state at RT are shown.

\begin{tabular}{|c|c|c|c|c|c|c|c|}
\hline \multirow{2}{*}{ Liquids } & \multirow[b]{2}{*}{ Temp. } & \multicolumn{2}{|c|}{ goO(r) } & \multicolumn{2}{|c|}{ gOD $(r)$} & \multicolumn{2}{|c|}{$\mathrm{g}_{\mathrm{DD}}(\mathrm{r})$} \\
\hline & & $1^{\text {st }}$ & $2^{\text {nd }}$ & $1^{\text {st }}$ & $2^{\text {nd }}$ & $1^{\text {st }}$ & $2^{\text {nd }}$ \\
\hline D-2-propanol & RT & $\begin{array}{c}2.90 \\
(2.75)\end{array}$ & $\begin{array}{c}4.95 \\
(4.70)\end{array}$ & $\begin{array}{c}1.95 \\
(1.82)\end{array}$ & $\begin{array}{c}3.40 \\
(3.30)\end{array}$ & $\begin{array}{l}2.55 \\
(2.36)\end{array}$ & $\begin{array}{c}4.55 \\
(4.60)\end{array}$ \\
\hline D-1-propanol & RT & $\begin{array}{c}2.95 \\
(2.75) \\
(2.77)\end{array}$ & $\begin{array}{c}5.20 \\
(4.70) \\
(4.82)\end{array}$ & $\begin{array}{c}2.04 \\
(1.82) \\
(1.86)\end{array}$ & $\begin{array}{c}3.60 \\
(3.30) \\
(3.34)\end{array}$ & $\begin{array}{c}2.66 \\
(2.36) \\
-\end{array}$ & $\begin{array}{c}4.64 \\
(4.60) \\
-\end{array}$ \\
\hline $\mathrm{D}_{2} \mathrm{O}$ & RT & 2.87 & 4.26 & 2.02 & 3.45 & 2.46 & 3.90 \\
\hline
\end{tabular}

Table 5. Main peak locations of $\mathrm{g}_{\alpha \beta}(\mathrm{r})$ in $\AA$. MD simulation data for $\mathrm{g}_{\mathrm{DD}}(\mathrm{r})$ not available. 
In the parenthesis the simulation results (Jorgensen, 1986; Takamuku et al, 2004) are shown. The comparison of distribution curves for 1- and 2-propanols reveals that the peak heights of 2-propanol are in general more while the peak positions are at a little bit smaller r. Another important point to note here is that NDIS (Neutron Diffraction Isotropic Substitution) experimental method enables evaluation of $\mathrm{g}_{\alpha \beta}(\mathrm{r})$ for $\mathrm{D}_{2} \mathrm{O}$ at $\mathrm{RT}$ (Soper et al, 1997). The first peak locations for goo(r), gOD $(r), g_{D D}(r)$ of $\mathrm{D}_{2} \mathrm{O}$ shown in the table agree reasonably well with those for two propanols. This agreement is expected and this also justifies the probable association model suggested here for liquid propanols at RT. Anyway, coming to the case of two propanols the differences in the first peak heights and small differences in peak locations, particularly for the second peaks could be enough to guess that the average intermolecular pair potential, if it could be extracted from experimental data, could be significantly different for the two propanols and this could possibly explain the significant differences in the thermodynamic and other properties of these two isomeric liquids.

\section{Conclusion}

The detailed molecular conformational and associational structures of liquids with big size molecules like propanols using neutron diffraction have been presented in this chapter. The neutron diffraction analysis is important as H-positions can be accurately seen here unlike $\mathrm{x}$ rays. Still today, the diffraction data analysis happens to be the most powerful tool for molecular as well as liquid structure analyses. The x-ray can not locate H-positions accurately but skeleton of the intermolecular structure is better seen than by neutrons where overlapping of several intra and intermolecular scattering terms occur. So a combined analysis with two diffraction data sets (neutrons and x-rays) is found to be most useful.

The data in the analysis reported here are reactor neutron data extended upto a q not more than $16 \AA^{-1}$, though the data have been claimed to be of good accuracy. It is however to be noted here that all the structural information, molecular and intermolecular are contained in this range. The data at higher q's (say $20 \AA^{-1}$ onwards as in TOF data) do not contain much information other than simple noise. The method of data analysis reported here is consistent and reasonably accurate. The analysis clearly indicates the molecular conformational differences in the two propanols and molecular associational similarities in them at RT. The average molecular association is shown to be hexameric rings. Such molecular association was first proposed for liquid methanol by Pauling (1967) and was supported for methanol and several other alcohols in liquid state by works from this laboratory (Sarkar \& Joarder, 1993, 1994; Karmakar et al, 1995; Nath et al, 2002). The justification of such structure for liquid methanol was given by Sarkar \& Joarder( 1993). The reason for the possibility of such structure in dominant form could be also found in Kashtanov et al's work (2005). It is pointed out there that the molecular orbitals of the six unit ring methanol structure show similarity to those of benzene ring indicating that H-bonding in methanol ring has significant amount of covalent contribution. Further, the electronic structure of methanol dimer is as polarized as the other chain structures and it is completely different from rings and as such the molecular dynamics based on potentials derived from methanol dimer does not predict ring structures. So it is expected that potentials which take into account the unique covalent contribution to H-bonding need to be used in simulation works for generating ring structures like hexameric rings as claimed in the different studies of liquid 
alcohols. The MC simulation work with refined H-bonding potential does predict the possibility of the presence of hexameric ring structures (Gonzalez et al, 2007).It is also to be noted here that earlier computer simulation (Jorgensen, 1986) yielded 1.91 and $1.92 \mathrm{H}$-bonds per molecule for 1-and 2-propanols respectively. The x-ray diffraction data (Takamuku et al, 2002, 2004) yield almost similar values (1.92 for 1-propanol and almost 2.0 for 2-propanol). Further, for liquid like methanol, the EPSR (Empirical Potential Structure Refinement) method (Yamaguchi et al, 1999) based on neutron diffraction data predicts $1.95 \pm 0.07$ \& $1.77 \pm 0.07 \mathrm{H}$-bonds per molecule and $6.27 \pm 0.7$ \& $5.5 \pm 1$ molecules per chain cluster respectively at $-80^{\circ} \mathrm{C} \& 25^{\circ} \mathrm{C}$ and these facts approximately agree with HRC model. It is however to be noted here that the other clusters like trimer, tetramer etc. in small proportions are also possible. The analysis for extraction of other structures via molecular cluster theory is in principle possible and could be carried out in near future. Further, provided the experimental data are available, the temperature and pressure effects on the molecular association could also be possibly studied as has been done recently for liquid methanol (Sahoo et al, 2010) and also possibly using MCSQ(Monte Carlo Structure Factor) technique (Sahoo \& Joarder, 2010).

\section{Acknowledgement}

The author thanks his collaborators, Dr. A. Sahoo and Dr. P. S. R. Krishna (BARC, India) for their assistance and contribution.

\section{References}

Abdel Aziz, N. E. \& Rogowski, F. (1964). Structure Estimation of n-Propyl Alcohol, Isopropyl Alcohol, Allylalcohol and Propargylalcohol in Vapor Phase by Electron Diffraction. Zeitschrift für Naturforschung, Vol.19b, No. 25 (June, 1964), pp.967-977, ISSN 0932-0776.

Adya, A. K., Bianchi, L. \& Wormald, C. J. (2000). The Structure of Liquid Methanol by H/D Substitution Technique of Neutron Diffraction. Journal of Chemical Physics, Vol. 112, No. 9(March, 2000), pp. 4231-4241, ISSN 0021-9606.

Akiyama, I., Ogawa, M., Takase, K., Takamuku, T., Yamaguchi, T. \& Ohtori, N.(2004). Liquid Structure of 1- Propanol by Molcular Dynamics Simulations and X-ray Scattering. Journal of Solution Chemistry, Vol. 33, No. 6/7 (June/ July, 2004), pp. 797809, ISSN 0095-9782.

Benson, S. W. (1996). Some Observations on the Structures of Liquid Alcohols and Their Heats of Vaporization. Journal of American Chemical Society, Vol. 118, No. 43 (October, 1996), pp 10645-10649, ISSN 0002-7863

Bertagnolli, H., Chieux, P. \& Zeidler, M. D. (n. d.). A Neutron-diffraction Study of Liquid Acetonitrile.Molecular Physics, Vol. 32. No. 3 (September, 1976), pp.759-773, ISSN 0026-8976.

Champeney, D. C., Joarder, R. N. \& Dore, J. C. (1986). Structural Study of Liquid D-glycerol by Neutron Diffraction. Molecular Physics, Vol. 58, No. 2 ( June, 1986), pp.337-347, ISSN 0026-8976.

Cuello, G. J., Talon, C., Bermejo, F. J. \& Cabrillo, C. (2002). Chemical Isomeric Effects on Propanol Glassy Sturctures. Applied Physics A. Vol. 74(Suppl.), pp. S552-S554, ISSN 0947-8396 
Egelstaff, P. A. (1987). Classical Fluids. In: Methods of Experimental Physics: Neutron Scattering, D. L. Price \& K. Skold(Eds.) , Vol. 23B, Accademic Press, San Diego, USA, ISBN 0-12-475969-6.

Frenkel, J. (1955). Kinetic Theory of Gases, Dover, New York, USA.

Gonzalez, M. V., Martin, H. S. \& Cobos, J. H.(2007). Liquid Methanol Monte Carlo Simulations with a Refined Potential which includes Polarizability, Nonadditivity, and Intramolecular Relaxation. Journal of Chemical Physics, Vol. 127, No. 22(December, 2007), pp.224507(14), ISSN 0021-9606.

Jorgensen, W. L. (1986). Optimized Intermolecular Potential Functions for Liquid Alcohols. Journal of Physical Chemistry, Vol.90, No.7 (n. d.), pp. 1276-1284, ISSN 0022-3654

Karmakar, A. K.,, Sarkar, S. \& Joarder, R. N. (1995). Molecular Clusters in Liquid tert-Butyl Alcohol at Room Temperature. Journal of Physical Chemistry, Vol. 99, No.45 (November, 1995), pp. 16501-16503, ISSN 0022-3659.

Kashtanov, S., Auguston, A., Rubensson, J. -E., Nordgren, J., Agren, H., Guo, J.-H. \& Luo, Y. (2005). Chemical and Electronic Structures of Liquid Methanol from X-ray Emission Spectroscopy and Density Functional Theory. Physical Review B, Vol. 71, No. 10 (March, 2005), pp. 104205(7), ISSN 1098-0121.

Magini, M., Paschina, G. \& Piccaluga, G. (1982). On the Structure of Methyl Alcohol at Room Temperature. Journal of Chemical Physics. Vol. 77, No. 4(August, 1982), pp.2051-2056, ISSN 0021-9606.

Mikusinska-Planner, A. (1977). X-ray Diffraction Study of the Structure of 1-Propanol at $25^{\circ} \mathrm{C}$. Acta Crystallography, Vol. A33,No. 3(May, 1977), pp. 433-437,ISSN 1600-5724.

Montague, D. G. \& Dore, J. C. (1986). Structural Studies of the Liquid Alcohols by Neutron Diffraction, IV $\mathrm{CD}_{3} \mathrm{OH}$ and $\mathrm{CD}_{3} \mathrm{OD}$. Molecular Physics. Vol. 57, No. 5 (n.d.), pp. 1035-1047, ISSN 0026-8976.

Narten, A. H. \& Habenchuss, A. (1984). Hydrogen Bonding in Liquid Methanol and Ethanol determined by X-ray Diffraction. Journal of Chemical Physics, Vol. 80, No. 7 (April, 1984), pp.3387-3391, ISSN 0021-9606.

Nath, P. P., Sarker, S., Krishna, P. S. R. \& Joarder, R. N. (2002). Intermolecular Structure of Liquid D-tert Butanol by Neutron Diffraction Data. Applied Physics A, Vol. 74(Suppl.), pp. S348-S351, ISSN 0947-8396

Pauling, L. (1967). The nature of Chemical Bond, $3^{\text {rd }}$. Edition, Oxford University, Oxford, UK, ISBN 0-8014-0333-2.

Ramos, M. A., Talon, C., Jimenez-Rioboo, R. J. \& Vieira, S.(2003). Low Temperature Specific Heat of Structural and Orientational Glasses of Simple Alcohols. Journal of Physics: Condensed Matter, Vol. 15 (March, 2003), pp. S1007-S1018, ISSN 0953-8984.

Sahoo, A., Nath. P. P., Bhagat, V., Krishna, P. S. R. \& Joarder, R. N. (2010). Effect of Temperature on the Molecular Association in Liquid D-Methanol using Neutron Diffraction Data. Physics and Chemistry of Liquids. Vol. 48, No. 4 (August, 2010), pp. 546-559, ISSN 0031-9104.

Sahoo, A., Sarkar, S., Bhagat, V., \& Joarder, R. N. (2009).The Probable Molecular Association in Liquid D-1-Propanol through Neutron Diffraction. Journal of Physical Chemistry A, Vol. 113, No. 17(April, 2009),pp.5160-5162, ISSN 1089-5639.

Sahoo, A., Sarkar, S., Bhagat, V., \& Joarder, R. N. (2008). Molecular Conformation and Structural Correlations of Liquid D-1-Propanol through Neutron Diffraction. Pramana-Journal of Physics, Vol. 71, No. 1(July, 2008), pp.133-141, ISSN 0304-4289. 
Sahoo, A., Sarkar, S., Krishna, P. S. R, \& Joarder, R. N.(2010). Molecular Conformation and Liquid Structure of 2-Propanol through Neutron Diffraction. Pramana-Journal of Physics, Vol. 74, No. 5(May, 2010), pp. 765-779, ISSN 0304-4289.

Sahoo, A. \& Joarder, R. N.(2010). Monte-Carlo Structure Factor (MCSQ) Calculation for Liquid Structure of H-bonded Molecular Liquids. Solid State Physics. Proceeding of the 55th DAE -Solid State Physics Symposium, 2010. AIP Conf. Proc. 1349, Vol. 55 (December, 2010) pp.521-522, ISBN 978-0-7354-0905-7.

Sahoo, A. (2011). Investigation of Molecular Conformation and Association in Some Hbonded Liquids through Neutron Diffraction. Ph. D. Dissertation, Jadavpur University( June, 2011), Kolkata, India.

Sarkar, S., \& Joarder, R. N. (1993). Molecular Clusters and Correlations in Liquid Methanol at Room Temperature. Journal of Chemical Physics, Vol. 99, No. 3(August, 1993), pp.2032-2039; Ibid. Molecular clusters in Liquid Ethanol at Room Temperature.Vol. 100, No.7(April,1994), pp.5118- 5122, ISSN 0021-9606.

Sarkar, S., Nath, P. P., \& Joarder, R. N. (2000). Orientation Correlation versus Cluster Correlation in Molecular Liquids-Signature through Diffraction Data. Physics letters A, Vol. 275, No. 1-2 (October, 2000)pp.138-141, ISSN 0375-9601.

Soper, A. K. (1996). Empirical Potential Monte Carlo Simulation of Fluid Structure. Chemical Physics, Vol. 202. No.2-3 (January, 1996), pp. 295-306, ISSN 0301-0104.

Soper, A. K., Bruni, F. \& Ricci, M. A. (1997). “Site-Site Pair Correlation Functions of Water from $25^{\circ} \mathrm{C}$ to $400^{\circ} \mathrm{C}$ : Revised Analysis of New and Old Diffraction Data" Journal of Chemical Physics, Vol. 106,No.1(January,1997), pp. 247-254, ISSN 0021-9606.

Sum, A. K. \& Sandler, S. I. (2000). Ab Initio Calculations of Cooperativity Effects on Clusters of Methanol, Ethanol, 1-Propanol and Methanethiol. Journal of Physical Chemistry A, Vol. 104, No. 6 (January, 2000), pp.1121-1129, ISSN 1089-5639.

Svishchev, I. M. \& Kusalik, P. G. (1994). Structure in Liquid Methanol from Spatial Distribution Functions. Journal of Chemical Physics, Vol. 100, No. 7(April, 1994), pp. 5165-5171, ISSN 0021-9606.

Tanaka, Y., Ohtomo, N., \& Arakawa, K.(1984). The Structure of Liquid Alcohols by Neutron Diffraction II. Molecular Structure of Ethylalcohol. Bulletin of Chemical Society of Japan, Vol. 57, No. 9(September, 1984), pp.2569-2573, ISSN 0009-2673.

Takamuku, T., Saisho, K., Aoki, S. \& Yamaguchi, T. (2002). Large-angle X-ray Scattering Investigation of the Structure of 2-Propanol-Water Mixtures. Zeitscript für Naturforschung.Vol. 57a, (n. d.), pp. 982-994, ISSN 0932-0784.

Takamuku, T., Maryyama, H., Watanabe, K., \& Yamaguchi, T.,(2004). Structure of 1Propanol -water Mixtures Investigated by Large-Angle X-ray Scattering Technique. Journal of Solution Chemistry, Vol. 33, No. 6/7(June/July2004), pp.641-660, ISSN 0095-9782.

Talon, C., Bermejo, F. J., Cabrillo, C., Cuello, G. S., Gonzalez, M. A., Richardson, J. W., Criado, A., Ramos, M. A., Vieira, S., Combrero, F. L., Gonzalez, L. M.(2002). Chemical Isomerism as a Key to Explore Free-energy Landscapes in Disordered Matter. Physical Review Letters, Vol. 88, No.11 (March, 2002), pp. 115506(4), ISSN 0031-9007.

Talon, C., Ramos, M. A., Vieira, S., Symyt'ko, I., Afonikova, N., Criado, A., Madariago, G. \& Bermejo, F. J.(2001). Themodynamic and Structural properties of the two Isomers of 
solid Propanol. Journal of Non-Crystalline Solids. Vol. 287,(n. d.) pp. 226-230, ISSN 0022-3093.

Yamaguchi, T., Hidaka, K., \& Soper, A. K.(1999). The Structure of Liquid Methanol Revisited: a Neutron Diffraction Experiment at $-80^{\circ} \mathrm{C}$ and $+25^{\circ} \mathrm{C}$. Molecular Physics, Vol. 96, No.8 (April, 1999), pp. 1159-1168; Ibid. ERRATUM The Structure of Liquid Methanol Revisited: a Neutron Diffraction Experiment at $-80 \mathrm{C}$ and +25 C. vol. 97, No. 4 (August, 1999), pp.603- 605, ISSN 0026-8976.

Zetterström, P. Dalborg, U., Delaplane, R. G. \& Howells, W. S. (1991). Neutron Diffraction Studies of Liquid Iso-Propanol. Physica Sripta, Vol. 44, (n. d.),pp.56-62, ISSN 00318949.

Zetterström, P. Dalborg, U., \& Howells, W. S. (1994). A Systematic Study of the Structure of Liquid Iso-Propanol by Time-of-Flight Neutron Diffraction. Molecular Physics, Vol. 81, No. 5, (October, 1994), pp.1187-1204, ISSN 0026-8976. 


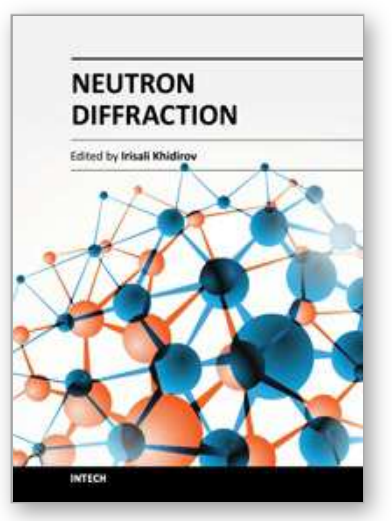

\author{
Neutron Diffraction \\ Edited by Prof. Irisali Khidirov
}

ISBN 978-953-51-0307-3

Hard cover, 286 pages

Publisher InTech

Published online 14, March, 2012

Published in print edition March, 2012

Now neutron diffraction is widely applied for the research of crystal, magnetic structure and internal stress of crystalline materials of various classes, including nanocrystalls. In the present book, we make practically short excursion to modern state of neutron diffraction researches of crystal materials of various classes. The book contains a helpful information on a modern state of neutron diffraction researches of crystals for the broad specialists interested in studying crystals and purposeful regulation of their service characteristics, since the crystal structure, basically, defines their physical and mechanical properties. Some chapters of the book have methodical character that can be useful to scientists, interested in possibilities of neutron diffraction. We hope, that results of last years presented in the book, can be a push to new ideas in studying of crystalline, magnetic structure and a macrostructure of usual crystal materials and nanocrystals. In turn, it can promote working out of new materials with new improved service characteristics and to origin of innovative ideas.

\title{
How to reference
}

In order to correctly reference this scholarly work, feel free to copy and paste the following:

R.N. Joarder (2012). The Molecular Conformations and Intermolecular Correlations in Positional Isomers 1and 2- Propanols in Liquid State Through Neutron Diffraction, Neutron Diffraction, Prof. Irisali Khidirov (Ed.), ISBN: 978-953-51-0307-3, InTech, Available from: http://www.intechopen.com/books/neutron-diffraction/themolecular-conformations-and-intermolecular-correlations-in-positional-isomers-1-and-2-propanols-

\section{INTECH}

open science | open minds

\author{
InTech Europe \\ University Campus STeP Ri \\ Slavka Krautzeka 83/A \\ 51000 Rijeka, Croatia \\ Phone: +385 (51) 770447 \\ Fax: +385 (51) 686166 \\ www.intechopen.com
}

\author{
InTech China \\ Unit 405, Office Block, Hotel Equatorial Shanghai \\ No.65, Yan An Road (West), Shanghai, 200040, China \\ 中国上海市延安西路65号上海国际贵都大饭店办公楼 405 单元 \\ Phone: +86-21-62489820 \\ Fax: $+86-21-62489821$
}


(C) 2012 The Author(s). Licensee IntechOpen. This is an open access article distributed under the terms of the Creative Commons Attribution 3.0 License, which permits unrestricted use, distribution, and reproduction in any medium, provided the original work is properly cited. 